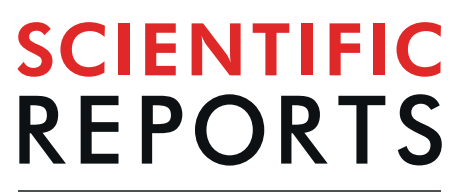

natureresearch

\title{
The Influence of the Variation in Sepsis Rate between Neonatal Intensive Care Units on Neonatal Outcomes in Very-Low-Birth- Weight Infants
}

\begin{abstract}
Tae-Jung Sung ${ }^{1}$, Jin A. Sohn ${ }^{2,3}$, Sohee $\mathrm{Oh}^{4} \&$ Jin A. Lee $\mathbb{D}^{2,3^{*}}$
Sepsis is commonly known to affect neonatal outcomes. We assessed how much center-to-center variability of the sepsis rate affects the outcomes of very-low-birth-weight infants (VLBWIs). 7,493 VLBWIs registered in the Korean Neonatal Network from 2013 to 2016 were classified into three groups according to the sepsis rate: low sepsis group (LS) $<25^{\text {th }}$ percentile versus intermediate sepsis group (IS) $25^{\text {th }}-75^{\text {th }}$ versus high sepsis group (HS) $\geq 75^{\text {th }}$. The incidence density of sepsis for the LS, IS, and HS groups were $1.17,3.17$, and 8.88 cases $/ 1,000$ person-days. After propensity score matching was done for multiple antenatal and perinatal factors, the odds ratio of death, moderate to severe bronchopulmonary dysplasia and/or death, periventricular leukomalacia, and survival without major morbidities for the HS group were 2.0 (95\% confidence interval 1.4-2.8), 1.9 (1.5-2.4), 1.5 (1.1-2.3) and 0.7 (0.5-0.8) when compared with the IS group, and 2.2 (1.6-3.2), 2.3 (1.8-2.9), 2.0 (1.3-2.9), and 0.7 $(0.6-0.9)$ when compared with the LS group. There were no significant differences in those outcomes between the LS and IS groups. Hence, nationwide quality improvements to control the sepsis rate especially in units with a high sepsis rate will be helpful to improve the outcomes of VLBWIs.
\end{abstract}

Sepsis is known to be associated with increased length of stay, mortality and morbidities of very-low-birth-weight (VLBW) preterm infants including bronchopulmonary dysplasia (BPD) and long-term neurodevelopmental impairment ${ }^{1-5}$. Nowadays, many efforts to reduce sepsis in the neonatal intensive care unit (NICU) are ongoing by nationwide quality improvement interventions including vigorous hand washing, catheter bundle management, increasing the diagnostic accuracy of sepsis and antibiotic stewardship ${ }^{6}$. However, it is still difficult to reduce the sepsis incidence to zero in NICU care because of the immature immunity systems of preterm infants and the different environments in each hospital which cannot be changed in a short time. Although the survival rate of VLBW infants is increasing by advances in neonatal care, the rate of sepsis is still higher in immature and smaller preterm infants.

There have been reports suggesting unit to unit differences in neonatal outcomes ${ }^{7}$, and such a unit difference is derived from differences in practice ${ }^{8-11}$. The sepsis rate usually differs from center to center ${ }^{1,9-11}$. Considering the adverse effect of sepsis on neonatal outcomes in preterm infants, knowing how much different the sepsis rate is between NICU units in South Korea is important to determine the necessity of managing nationwide quality improvements to control sepsis and reduce such gaps between units.

Since 2013, almost all the NICUs in South Korea have been participating in the nationwide Korean Neonatal Network (KNN). According to an analysis of the KNN database in 2014, the sepsis rate in VLBW infants in South Korea was $21.1 \%$, and the late-onset sepsis (LOS) rate was $19.4 \%$ with a $16.1 \%$ mortality rate ${ }^{12}$. Such a sepsis rate is similar to that of the Canadian Neonatal Network, however, higher than that of the Neonatal Research Network of $\operatorname{Japan}^{13}$. We still do not know how much the sepsis rate differs from center to center in South Korea. Moreover, we

\footnotetext{
${ }^{1}$ Department of Pediatrics, Hallym University Medical Center kangnam Sacred Heart Hospital, Seoul, South Korea. ${ }^{2}$ Department of Pediatrics, Seoul National University College of Medicine, Seoul, South Korea. ${ }^{3}$ Department of Pediatrics, SMG-SNU Boramae Medical Center, Seoul, South Korea. ${ }^{4}$ Department of Biostatistics, SMG-SNU Boramae Medical Center, Seoul, South Korea. *email: ljinna@snu.ac.kr
} 


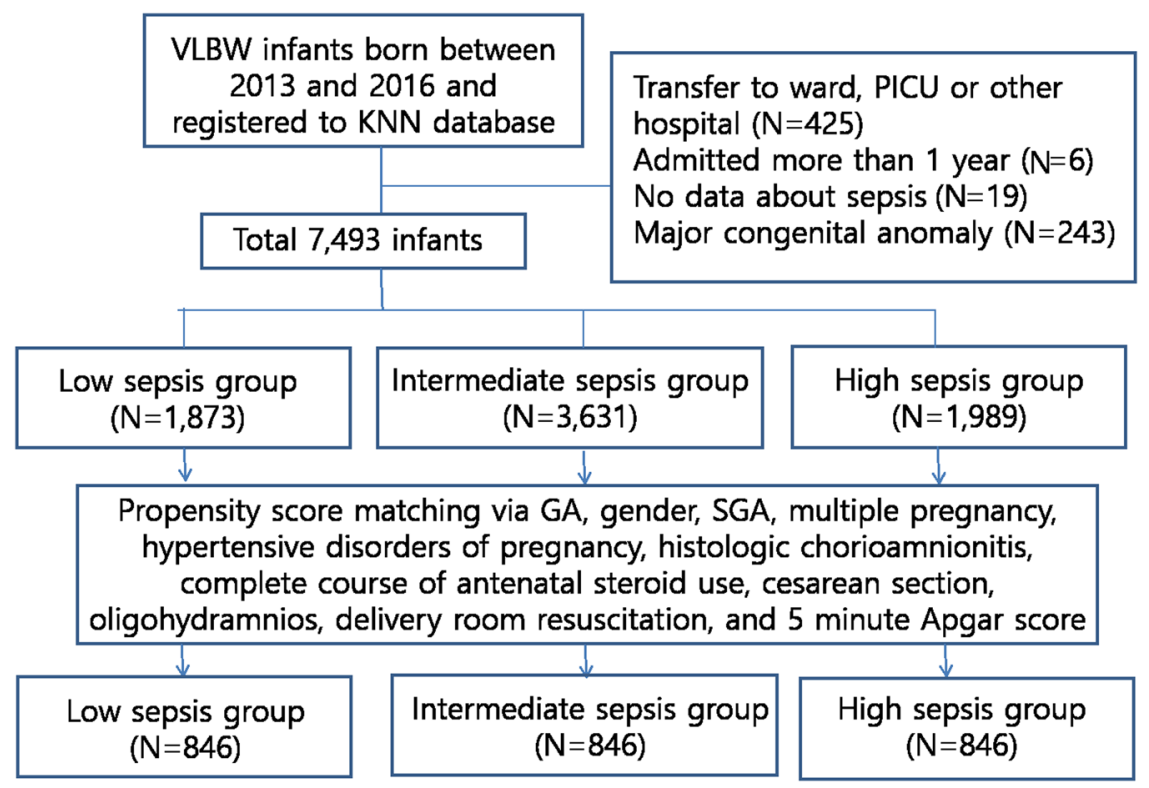

Figure 1. The study population. A total of 7,493 very-low-birth-weight infants born between 2013 and 2016 and registered in the Korean Neonatal Network database were included. After the propensity score matching by gestational age, gender, small for gestational age, multiple pregnancies, cesarean section, hypertensive disorders of pregnancy, histologic chorioamnionitis, oligohydramnios, complete course of antenatal steroid use, delivery room resuscitation, and 5-minute Apgar score, 846 neonates were included each in the low sepsis, intermediate sepsis, and high sepsis groups.

do not know whether such differences in the sepsis rate are associated with a worse neonatal outcome in VLBW infants. Thus, it is necessary to determine the real status of the unit variation in the sepsis rate or the incidence density using the KNN database before starting a nationwide intervention for quality improvement to control sepsis in NICUs in South Korea.

Hence, the aim of this study was to show how much the sepsis rate or the incidence density of sepsis is different between NICUs in South Korea and how this unit variation affects the neonatal outcomes in VLBW infants.

\section{Results}

Population. A total of 7,493 VLBW infants from 67 hospitals were included after the exclusion of 693 infants: 425 infants transferred to a ward, pediatric intensive care unit or other hospital; 6 infants admitted more than one year; 19 infants with no information about sepsis, and 243 infants with a major congenital anomaly. The number of infants classified as the low sepsis group (LS), intermediate sepsis group (IS), and high sepsis group (HS) was $1,873,3,631$, and 1,989 infants in each group. The number of hospitals included in the LS, IS, and HS group were 16,35 , and 16 , respectively. After propensity score matching for gestational age (GA), gender, small for gestational age (SGA), multiple pregnancies, cesarean section, hypertensive disorders of pregnancy, histologic chorioamnionitis (HCA), oligohydramnios, complete course of antenatal corticosteroid (ACS) use, delivery room resuscitation, and 5 minute Apgar score, 846 infants were included in each group for the analysis (Fig. 1).

General characteristics about sepsis. The total incidence density of sepsis in the 7,493 VLBW infants was 3.83 cases per 1,000 person-days and 1,461 infants (19.5\%) experienced sepsis during NICU hospitalization. In detail, 1,393 infants (18.6\%) suffered from bacterial sepsis, and 139 infants (1.9\%) suffered from fungal sepsis. Additionally, 299 infants (4.0\%) experienced sepsis more than one time during hospitalization. Moreover, 130 neonates $(1.7 \%)$ suffered from early-onset sepsis, and 1,331 neonates (17.8\%) suffered from LOS. The median value for the first postnatal day of sepsis was 15 days after birth (interquartile range 8, 28 days).

The incidence density of sepsis in each group was 1.17 cases per 1,000 person-days in the LS group, 3.17 cases per 1,000 person-days in the IS group, and 8.88 cases per 1,000 person-days in the HS group. Between the three groups, there was a significant difference in the percentage of sepsis $(\mathrm{P}=0.001)$. Early-onset sepsis $(\mathrm{EOS})$ was less prevalent in the LS group when compared with the IS or HS group $(\mathrm{P}=0.002)$. The late-onset sepsis (LOS) rate was also significantly different between the three groups $(\mathrm{P}<0.001)$, and the post-hoc analysis showed that there was also differences between the LS and IS, LS and HS, and IS and HS groups, respectively. LOS rate was highest in HS group and lowest in LS group. Additionally, the percentage of multiple episodes of sepsis was also significantly different between the three groups. There was no difference in the first postnatal day of sepsis between the three groups (Table 1).

After the propensity score matching, the incidence density of sepsis in 2,538 matched VLBW infants was 3.94 cases per 1,000 person-days, and the incidence density of sepsis in each matched group was 1.27 cases per 1,000 person-days in the LS group, 2.99 cases per 1,000 person-days in the IS group, and 9.04 cases per 1,000 person-days in the HS group. The sepsis rate was also higher in the HS group, which was mainly due to the 


\begin{tabular}{|c|c|c|c|c|c|c|c|c|}
\hline & \multicolumn{8}{|c|}{ Propensity score matching } \\
\hline & \multicolumn{4}{|c|}{ Unmatched data set $(\mathrm{N}=7,493)$} & \multicolumn{4}{|c|}{ Matched data set $(\mathrm{N}=2,538)$} \\
\hline & $\begin{array}{l}\text { Low sepsis } \\
\text { group } \\
(\mathrm{N}=1,873)\end{array}$ & $\begin{array}{l}\text { Intermediate } \\
\text { sepsis group } \\
(\mathbf{N}=\mathbf{3}, \mathbf{6 3 1})\end{array}$ & $\begin{array}{l}\text { High sepsis } \\
\text { group } \\
(\mathrm{N}=1,989)\end{array}$ & $P$-value & \begin{tabular}{|l|} 
Low sepsis \\
group \\
$(\mathrm{N}=846)$
\end{tabular} & $\begin{array}{l}\text { Intermediate } \\
\text { sepsis group } \\
(\mathrm{N}=846)\end{array}$ & $\begin{array}{l}\text { High sepsis } \\
\text { group } \\
(\mathrm{N}=846)\end{array}$ & $P$-value \\
\hline $\begin{array}{l}\text { Sepsis incidence density } \\
\text { (cases per } 1,000 \text { person-day) }\end{array}$ & 1.17 & 3.17 & 8.88 & $<0.001^{* * *, \dagger}$ & 1.27 & 2.99 & 9.04 & $<0.001^{*, * *, \dagger}$ \\
\hline Sepsis, total, number (\%) & $125(6.7 \%)$ & $656(16.9 \%)$ & $721(36.2 \%)$ & $<0.001^{* * * *, \dagger}$ & $65(7.7 \%)$ & $137(16.2 \%)$ & $320(37.8 \%)$ & $<0.001^{*, * *, \dagger}$ \\
\hline Early-onset & $26(1.4 \%)$ & $52(1.4 \%)$ & $52(2.6 \%)$ & \multirow{2}{*}{$<0.001^{* * *, \dagger}$} & $19(2.2 \%)$ & $13(1.5 \%)$ & $21(2.5 \%)$ & \multirow{2}{*}{$<0.001^{* * *, \dagger}$} \\
\hline Late-onset & $99(5.3 \%)$ & $563(15.5 \%)$ & $669(33.6 \%)$ & & $46(5.4 \%)$ & $124(14.7 \%)$ & $299(35.3 \%)$ & \\
\hline Sepsis, bacterial, number (\%) & $114(6.1 \%)$ & $580(16.0 \%)$ & $699(35.1 \%)$ & $<0.001^{* * * *, \dagger}$ & $60(7.1 \%)$ & $129(15.2 \%)$ & $314(37.1 \%)$ & $<0.001^{*, * *, \dagger}$ \\
\hline Sepsis, Fungal, number (\%) & $11(0.6 \%)$ & $63(1.7 \%)$ & $65(3.3 \%)$ & $<0.001^{*, * *, \dagger}$ & $5(0.6 \%)$ & $10(1.2 \%)$ & $23(2.7 \%)$ & $0.001^{* *}$ \\
\hline Sepsis, multiple, number (\%) & $18(1.0 \%)$ & $112(3.1 \%)$ & $169(8.5 \%)$ & $<0.001^{*, * *, \dagger}$ & $9(1.1 \%)$ & $28(3.3 \%)$ & $74(8.7 \%)$ & $<0.001^{*, * *, \dagger}$ \\
\hline $\begin{array}{l}\text { First postnatal day of } \\
\text { sepsis(days) }\end{array}$ & $14[5,27]$ & $15[7,28]$ & $15[8,27]$ & 0.172 & $13[0,23]$ & $14[7,27]$ & $16[9,29]$ & $0.029^{* *}$ \\
\hline
\end{tabular}

Table 1. General characteristics about sepsis in the study population. Propensity score matching via gestational age, gender, small for gestational age, multiple pregnancies, cesarean section, hypertensive disorders of pregnancy, histologic chorioamnionitis, oligohydramnios, complete course of antenatal corticosteroid use, delivery room resuscitation, and 5 minute Apgar score. Kruskal-Wallis test or chi-square test in both propensity score unmatched population and propensity score matched population. $* \mathrm{P}<0.05$ between low sepsis group and intermediate sepsis group. ${ }^{* * \mathrm{P}}<0.05$ between low sepsis group and high sepsis group. ${ }^{\dagger} \mathrm{P}<0.05$ between intermediate sepsis group and high sepsis group.

increased incidence of LOS. The first postnatal day of sepsis was later in the HS group when compared with the LS group $(\mathrm{P}=0.029)$ (Table 1$)$.

Differences between the three groups before the propensity score matching. Maternal demographics and neonatal characteristics of the three groups. GA and birthweight were higher in the LS group when compared with those of the IS and HS groups. There was no difference in the gender proportion between the three groups. Maternal hypertensive disorders of pregnancy and SGA were more frequent in the LS group when compared with those of the IS and HS groups. Less infants received a complete course of ACS in the HS group when compared with the LS and IS groups. There was no difference in the frequency of delivery room resuscitation between the three groups; however, the Apgar score at 1 and 5 minutes was significantly higher in the LS group when compared with those of the IS and HS groups (Table 2). When we compared the distribution of groups according to the mean annual number of VLBW infants registered in $\mathrm{KNN}$, there was no significant differences between the LS, IS, and HS groups (Table 3$)$. The median groups $\left(25^{\text {th }}, 75^{\text {th }}\right.$ percentile) of the mean annual number of VLBW infants in the LS, IS, and HS groups were group 6 (group 4, group 6), group 6 (group 3, group 7), and group 5 (group 4, group 6).

Neonatal outcomes of the three groups. Respiratory distress syndrome (RDS), patent ductus arteriosus (PDA) with treatment, periventricular leukomalacia (PVL), and moderate to severe bronchopulmonary dysplasia (BPD) were more frequent in the HS group when compared with the LS and IS groups. There was a serial increase in the rate of multiple courses of surfactant use, hypotension within one week after birth, necrotizing enterocolitis (NEC) $\geq$ stage 2, intraventricular hemorrhage (IVH) $\geq$ grade 3 , severe BPD, BPD with postnatal steroid use, pulmonary hypertension requiring treatment, and mortality from the LS and IS to the HS group (Table 4). There were no significant differences in the duration of hospitalization between the three groups; however, it was shorter in the LS group when compared with the IS and HS groups in the survivors. There was also a serial increase in the duration of respiratory care, invasive ventilator care, and days to full feeding both in the total neonates and in the survivors from the LS and IS to the HS group (Table 4).

Differences between the three groups after the propensity score matching. Maternal demographics and neonatal characteristics of the three groups. After the propensity score matching, there was no significant difference in the maternal and neonatal demographic characteristics between the three groups. Only the rate of in-vitro fertilization was higher in the LS group when compared with the HS group (Table 2).

Neonatal outcomes. After the propensity score matching, surfactant use, hypotension within one week, PVL, moderate to severe BPD and severe BPD were more frequent in the HS group when compared with the LS and IS groups. Mortality was also higher in the HS group when compared with the LS or IS group. The length of stay in hospitals for the survivors was not different between the three groups; however, the duration of invasive ventilator care and the duration of total respiratory care were longer in the HS group when compared with the LS and IS groups in the survivors. Days to full feeding were also longer in the HS group (Table 4).

Both univariate logistic regression analysis after the propensity score matching and multivariate logistic regression analysis with random intercepts adjusting for GA and the hospital groups according to the mean annual number of VLBW infants registered in the KNN after the propensity score matching showed an increased odds ratio $(\mathrm{OR},>1)$ for mortality, moderate to severe BPD or death, and PVL in HS group when compared 


\begin{tabular}{|c|c|c|c|c|c|c|c|c|}
\hline & \multicolumn{8}{|c|}{ Propensity score matching } \\
\hline & \multicolumn{4}{|c|}{ Unmatched data set $(\mathrm{N}=7,493)$} & \multicolumn{4}{|c|}{ Matched data set $(\mathrm{N}=2,538)$} \\
\hline & $\begin{array}{l}\text { Low sepsis group } \\
(\mathrm{N}=1,873)\end{array}$ & $\begin{array}{l}\text { Intermediate } \\
\text { sepsis group } \\
(\mathrm{N}=3,631)\end{array}$ & $\begin{array}{l}\text { High sepsis } \\
\text { group } \\
(\mathrm{N}=1,989)\end{array}$ & P-value & $\begin{array}{l}\text { Low sepsis group } \\
(\mathrm{N}=846)\end{array}$ & $\begin{array}{l}\text { Intermediate } \\
\text { sepsis group } \\
(\mathrm{N}=\mathbf{8 4 6})\end{array}$ & $\begin{array}{l}\text { High sepsis group } \\
(\mathrm{N}=\mathbf{8 4 6})\end{array}$ & P-value \\
\hline \multicolumn{9}{|l|}{ Mother-related characteristics } \\
\hline Maternal Age & $33[30,35]$ & $33[30,35]$ & $33[30,36]$ & 0.175 & $33[30,35]$ & $33[31,36]$ & $33[30,36]$ & 0.446 \\
\hline Multiple pregnancy & $636(34.0 \%)$ & $1,368(37.7 \%)$ & $692(34.8 \%)$ & $0.011^{*}$ & $280(33.1 \%)$ & $285(33.7 \%)$ & $282(33.3 \%)$ & 0.967 \\
\hline Cesarean section & $1,485(79.3 \%)$ & $2,726(75.1 \%)$ & $1,629(81.9 \%)$ & $<0.001^{*, \dagger}$ & $690(81.6 \%)$ & $687(81.2 \%)$ & $685(81.0 \%)$ & 0.952 \\
\hline In vitro fertilization & $408(21.8 \%)$ & $922(25.4 \%)$ & $405(20.4 \%)$ & $<0.001^{*, \dagger}$ & $204(24.1 \%)$ & $182(21.5 \%)$ & $153(18.1 \%)$ & $0.010^{* * *}$ \\
\hline Gestational diabetes & $142(7.6 \%)$ & $294(8.1 \%)$ & $140(7.0 \%)$ & 0.356 & $63(7.4 \%)$ & $80(9.5 \%)$ & $68(8.0 \%)$ & 0.306 \\
\hline $\begin{array}{l}\text { Hypertensive disorder of } \\
\text { pregnancy }\end{array}$ & $461(24.6 \%)$ & $745(20.5 \%)^{*}$ & $384(19.3 \%)$ & $<0.001^{*, * *}$ & $173(20.4 \%)$ & $182(21.5 \%)^{*}$ & $190(22.5 \%)$ & 0.602 \\
\hline Histologic chorioamnionitis & $526(30.5 \%)$ & $1,083(35.9 \%)$ & $499(33.2 \%)$ & $0.001^{*}$ & $276(32.6 \%)$ & $287(33.9 \%)$ & $287(33.9 \%)$ & 0.807 \\
\hline Oligohydramnios & $249(13.9 \%)$ & $539(16.7 \%)$ & $208(11.4 \%)$ & $<0.001^{*, \dagger}$ & $110(13.0 \%)$ & $100(11.8 \%)$ & $115(13.6 \%)$ & 0.539 \\
\hline \multicolumn{9}{|l|}{ Neonate-related characteristics } \\
\hline Gestational age at birth (weeks) & $29^{+4}\left[27^{+3}, 31^{+3}\right]$ & $28^{+6}\left[26^{+4}, 30^{+5}\right]$ & $28^{+4}\left[26^{+4}, 30^{+4}\right]$ & $<0.001^{*, * *}$ & $28^{+6}\left[27^{+0}, 30^{+4}\right]$ & $28^{+6}\left[27^{+0}, 30^{+3}\right]$ & $28^{+5}\left[27^{+1}, 30^{+3}\right]$ & 0.896 \\
\hline Birthweight (g) & $1,190[950,1,370]$ & $1,120[850,1.320]$ & $1,120[870,1,320]$ & $<0.001^{*, * *}$ & $1,150[920,1,340]$ & $1,120[898,1.310]$ & $1,120[890,1,320]$ & 0.262 \\
\hline Male gender & $941(50.2 \%)$ & $1,806(49.7 \%)$ & $999(50.2 \%)$ & 0.912 & $437(51.7 \%)$ & $417(49.3 \%)$ & $428(50.6 \%)$ & 0.622 \\
\hline Small for gestational age & $553(29.5 \%)$ & $941(25.9 \%)$ & $439(22.1 \%)$ & $<0.001^{*, * *, \dagger}$ & $174(20.6 \%)$ & $171(20.2 \%)$ & $176(20.8 \%)$ & 0.955 \\
\hline Steroid, complete & $832(59.3 \%)$ & $1,733(59.9 \%)$ & $747(51.6 \%)$ & $<0.001^{* *, \dagger}$ & $489(57.8 \%)$ & $467(55.2 \%)$ & $457(54.0 \%)$ & 0.277 \\
\hline Delivery room resuscitation & $70(3.8 \%)$ & $162(4.5 \%)$ & $91(4.6 \%)$ & 0.351 & $34(4.0 \%)$ & $26(3.1 \%)$ & $31(3.7 \%)$ & 0.572 \\
\hline Apgar score at $1 \mathrm{~min}$ & $5[4,6]$ & $5[3,6]$ & $5[3,6]$ & $<0.001^{*, * *}$ & $5[4,6]$ & $5[3,7]$ & $5[3,6]$ & 0.099 \\
\hline Apgar score at $5 \mathrm{~min}$ & $7[6,8]$ & $7[6,8]$ & $7[6,8]$ & $<0.001^{*, * *}$ & $7[6,8]$ & $7[6,8]$ & $7[6,8]$ & 0.264 \\
\hline
\end{tabular}

Table 2. Maternal demographics and neonatal characteristics in the study population. Propensity score matching via gestational age, gender, small for gestational age, multiple pregnancies, cesarean section, hypertensive disorders of pregnancy, histologic chorioamnionitis, oligohydramnios, complete course of antenatal corticosteroid use, delivery room resuscitation, and 5 minute Apgar score. Kruskal-Wallis test or chisquare test in both propensity score unmatched population and propensity score matched population. $* \mathrm{P}<0.05$ between low sepsis group and intermediate sepsis group. $* * \mathrm{P}<0.05$ between low sepsis group and high sepsis group. ${ }^{\dagger} \mathrm{P}<0.05$ between intermediate sepsis group and high sepsis group.

\begin{tabular}{|l|l|l|l|}
\hline Groups & $\begin{array}{l}\text { Low sepsis } \\
\text { group } \\
(\mathbf{N = 1 , 8 7 3 )}\end{array}$ & $\begin{array}{l}\text { Intermediate } \\
\text { sepsis group } \\
(\mathbf{N = 3 , 6 3 1 )}\end{array}$ & $\begin{array}{l}\text { High sepsis } \\
\text { group } \\
(\mathbf{N = 1 , 9 8 9 )}\end{array}$ \\
\hline 1 & $8(0.4 \%)$ & $124(3.4 \%)$ & $6(0.3 \%)$ \\
\hline 2 & $118(6.3 \%)$ & $384(10.6 \%)$ & $138(6.9 \%)$ \\
\hline 3 & $285(15.2 \%)$ & $579(15.9 \%)$ & $156(7.8 \%)$ \\
\hline 4 & $200(10.7 \%)$ & $264(7.3 \%)$ & $426(21.4 \%)$ \\
\hline 5 & $158(8.4 \%)$ & $384(10.6 \%)$ & $401(20.2 \%)$ \\
\hline 6 & $716(38.2 \%)$ & $635(17.5 \%)$ & $406(20.4 \%)$ \\
\hline 7 & $388(20.7 \%)$ & $1261(34.7 \%)$ & $456(22.9 \%)$ \\
\hline $\begin{array}{l}\text { Median group }\left(25^{\text {th }}\right. \\
75^{\text {th }} \text { percentile) }\end{array}$ & $\begin{array}{l}\text { Group 6 } \\
(\text { Group 4, }\end{array}$ & $\begin{array}{l}\text { Group 6(Group } \\
\text { Group 6) }\end{array}$ & $\begin{array}{l}\text { Group 5 } \\
\text { (Group 4, }\end{array}$ \\
\hline
\end{tabular}

Table 3. Distribution of groups according to the mean annual number of very-low-birth-weight infants registered in Korean Neonatal Network among three groups. Group 1; mean annual very-low-birthweight infants $\langle 10$ patients per year, Group $2 ; \geq 10$ and $<20$, Group $3 ; \geq 20$ and $<30$, Group $4 ; \geq 30$ and $<40$, Group 5; $\geq 40$ and $<50$, Group $6 ; \geq 50$ and $<100$, Group $7 ; \geq 100$. P-value $=0.051$ by Kruskal-Wallis test.

with IS group and with LS group. The OR of survival without major morbidities in the HS group was 0.7 when compared with the IS group and 0.7 with LS group. However, those outcomes were not much different when compared between the IS and LS groups (Table 5).

Differences in the distribution of pathogens between the three groups. There were significant differences in the distribution of pathogens between the three groups both in the propensity score unmatched group $(\mathrm{P}=0.001)$ and in the propensity score matched group $(\mathrm{P}<0.001)$. The proportion of sepsis by gram positive organisms was higher, and the proportion of sepsis by gram negative organisms was lower in the HS group when compared with the IS and LS groups. After the propensity score matching, the rate of gram-negative sepsis 


\begin{tabular}{|c|c|c|c|c|c|c|c|c|}
\hline & \multicolumn{8}{|c|}{ Propensity score matching } \\
\hline & \multicolumn{4}{|c|}{ Unmatched data set $(\mathrm{N}=7,493)$} & \multicolumn{4}{|c|}{ Matched data set $(\mathrm{N}=2,538)$} \\
\hline & $\begin{array}{l}\text { Low sepsis } \\
\text { group } \\
(\mathrm{N}=1,873) \\
\end{array}$ & \begin{tabular}{|l|} 
Intermediate \\
sepsis group \\
$(\mathrm{N}=3,631)$ \\
\end{tabular} & $\begin{array}{l}\text { High sepsis } \\
\text { group } \\
(\mathrm{N}=1,989) \\
\end{array}$ & P-value & \begin{tabular}{|l|} 
Low sepsis \\
group \\
$(\mathrm{N}=846)$ \\
\end{tabular} & \begin{tabular}{|l|} 
Intermediate \\
sepsis group \\
$(\mathrm{N}=846)$ \\
\end{tabular} & \begin{tabular}{|l|} 
High sepsis \\
group \\
$(\mathrm{N}=846)$ \\
\end{tabular} & P-value \\
\hline Respiratory distress syndrome & $1,396(74.0 \%)$ & $2,689(74.1 \%)$ & $1,728(86.9 \%)$ & $<0.001^{* *, \dagger}$ & $675(79.8 \%)$ & $623(73.6 \%)$ & $743(87.8 \%)$ & $<0.001^{*, * *, \dagger}$ \\
\hline Surfactant use & $1,382(73.8 \%)$ & $2,781(76.6 \%)$ & $1,713(86.1 \%)$ & $<0.001^{* *, \dagger}$ & $682(80.6 \%)$ & $651(77.0 \%)$ & $739(87.4 \%)$ & $<0.001^{* *, \dagger}$ \\
\hline PDA with treatment & $622(41.2 \%)$ & $1,215(42.1 \%)$ & $813(50.8 \%)$ & $<0.001^{* *, \dagger}$ & $306(46.6 \%)$ & $297(44.3 \%)$ & $341(51.0 \%)$ & $0.045^{\ddagger}$ \\
\hline Hypotension within one week & $299(16.0 \%)$ & $786(21.6 \%)$ & $620(31.2 \%)$ & $<0.001^{*, * *, \dagger}$ & $140(16.5 \%)$ & $174(20.6 \%)$ & $250(29.6 \%)$ & $<0.001^{* *, \dagger}$ \\
\hline NEC $\geq$ stage 2 & $69(3.7 \%)$ & $222(6.1 \%)$ & $163(8.2 \%)$ & $<0.001^{*, * *, \dagger}$ & $33(3.9 \%)$ & $43(5.1 \%)$ & $64(7.6 \%)$ & $0.003^{* *}$ \\
\hline Isolated intestinal perforation & $12(0.6 \%)$ & $71(2.0 \%)$ & $50(2.5 \%)$ & $<0.001^{*, * *}$ & $5(0.6 \%)$ & $14(1.7 \%)$ & $22(2.6 \%)$ & $0.005^{* *}$ \\
\hline $\mathrm{IVH} \geq$ grade 3 & $92(5.0 \%)$ & $314(8.9 \%)$ & $213(11.0 \%)$ & $<0.001^{*, * *, \dagger}$ & $40(4.8 \%)$ & $61(7.4 \%)$ & $80(9.7 \%)$ & $0.001^{* *}$ \\
\hline PVL & $105(5.7 \%)$ & $244(7.0 \%)$ & $181(9.4 \%)$ & $<0.001^{* *, \dagger}$ & $55(6.6 \%)$ & $55(6.7 \%)$ & $84(10.2 \%)$ & $0.008^{* *, \dagger}$ \\
\hline Moderate to severe BPD & $385(22.4 \%)$ & $811(25.3 \%)$ & $580(34.8 \%)$ & $<0.001^{* *, \dagger}$ & $193(24.6 \%)$ & $197(25.7 \%)$ & $255(34.9 \%)$ & $<0.001^{* *, \dagger}$ \\
\hline Severe BPD & $186(10.8 \%)$ & $486(15.2 \%)$ & $355(21.3 \%)$ & $<0.001^{*, * *, \dagger}$ & $94(12.0 \%)$ & $104(13.6 \%)$ & $155(21.2 \%)$ & $<0.001^{* *, \dagger}$ \\
\hline BPD with steroid use & $206(11.0 \%)$ & $639(17.6 \%)$ & $514(25.8 \%)$ & $<0.001^{*, * *, \dagger}$ & $86(10.2 \%)$ & $140(16.5 \%)$ & $214(25.3 \%)$ & $<0.001^{*, * *, \dagger}$ \\
\hline $\begin{array}{l}\text { Pulmonary hypertension requiring } \\
\text { treatment }\end{array}$ & $75(4.0 \%)$ & $227(6.3 \%)$ & $187(9.4 \%)$ & $<0.001^{*, * *, \dagger}$ & $47(5.6 \%)$ & $54(6.4 \%)$ & $77(9.1 \%)$ & $0.012^{* *}$ \\
\hline ROP needs surgery or VEGF & $143(12.7 \%)$ & $336(14.5 \%)$ & $167(14.6 \%)$ & 0.342 & $83(16.8 \%)$ & $76(14.3 \%)$ & $76(16.4 \%)$ & 0.500 \\
\hline Death & $152(8.1 \%)$ & $451(12.4 \%)$ & $344(17.3 \%)$ & $<0.001^{*, * *, \dagger}$ & $67(7.9 \%)$ & $87(10.3 \%)$ & $123(14.5 \%)$ & $<0.001^{* *, \dagger}$ \\
\hline Discharge with respiratory support & $261(15.2 \%)$ & $562(17.7 \%)$ & $319(19.4 \%)$ & $0.005^{* *}$ & $129(16.6 \%)$ & $136(17.9 \%)$ & $152(21.0 \%)$ & 0.075 \\
\hline Hospital day & $56[40,79]$ & $58[38,84]$ & $57[37,79]$ & 0.067 & $61[44,83]$ & $59[41,82]$ & $58[41,79]$ & $0.031^{* *}$ \\
\hline Duration of invasive ventilator care & $2[0,8]$ & $3[0,17]$ & $4[1,19]$ & $<0.001^{*, * *, \dagger}$ & $2[0,9]$ & $3[0,15]$ & $4[1,18]$ & $<0.001^{* *, \dagger}$ \\
\hline Duration of total respiratory support & $19[5,46]$ & $25[6,55]$ & $31[10,58]$ & $<0.001^{*, *,+}$ & $25[7,51]$ & $28[7,55]$ & $32[11,57]$ & $<0.001^{* *, \dagger}$ \\
\hline Days to full feeding & $13[8,21]$ & $15[8,29]$ & $19[10,35]$ & $<0.001^{*, * *, \dagger}$ & $14[9,24]$ & $15[8,29]$ & $19[10,35]$ & $<0.001^{* *, \dagger}$ \\
\hline \multicolumn{9}{|l|}{ In survivors } \\
\hline Hospital day & $58[43,80]$ & $62[45,88]$ & $62[46,84]$ & $<0.001^{* * * *}$ & $64[47,84]$ & $62[45,84]$ & $62[47,82]$ & 0.429 \\
\hline Duration of invasive ventilator care & $2[0,7]$ & $2[0,14]$ & $3[1,17]$ & $<0.001^{*, * *, \dagger}$ & $2[0,8]$ & $3[0,12]$ & $3[1,17]$ & $<0.001^{* *, \dagger}$ \\
\hline Duration of total respiratory support & $21[5,47]$ & $28[6,57]$ & $35[12,61]$ & $<0.001^{*, * *, \dagger}$ & $27[7,53]$ & $30[8,56]$ & $35[12,59]$ & $<0.001^{* *, \dagger}$ \\
\hline Days to full feeding & $12[8,21]$ & $15[8,29]$ & $18[10,34]$ & $<0.001^{*, *,+\dagger}$ & $14[9,24]$ & $15[8,29]$ & $19[10,35]$ & $<0.001^{* *, \dagger}$ \\
\hline
\end{tabular}

Table 4. Neonatal outcomes in the study population. Propensity score matching via gestational age, gender, small for gestational age, multiple pregnancies, cesarean section, hypertensive disorders of pregnancy, histologic chorioamnionitis, oligohydramnios, complete course of antenatal corticosteroid use, delivery room resuscitation, and 5 minute Apgar score. Kruskal-Wallis test or chi-square test in both propensity score unmatched population and propensity score matched population. $* \mathrm{P}<0.05$ between low sepsis group and intermediate sepsis group. ${ }^{* *} \mathrm{P}<0.05$ between low sepsis group and high sepsis group. ${ }^{\dagger} \mathrm{P}<0.05$ between intermediate sepsis group and high sepsis group. $¥$ Not statistically significant after Bonferroni correction. PDA; patent ductus arteriosus, BPD; bronchopulmonary dysplasia, IVH; intraventricular hemorrhage, PVL; periventricular leukomalacia, NEC; necrotizing enterocolitis, ROP; retinopathy of prematurity, VEGF; vasculoendothelial growth factor.

was lower in the HS group when compared with the LS group. There was no significant difference in the rate of fungal sepsis between the three groups (Table 6).

Differences between the three groups when we excluded the infants with EOS. The sepsis incidence density and the sepsis rate were serially increased from the LS and IS to the HS group both before and after propensity score matching (Supplement Table 1). When we performed the same analyses in infants without EOS, there were significant differences in GA, birthweight, multiple pregnancy, cesarean section, hypertensive disorder of pregnancy, SGA, HCA, oligohydramnios, complete course of ACS use, and 1 minute and 5 minute Apgar scores. After propensity score matching was done, there were no significant differences between the LS, IS, and HS groups in maternal demographics and neonatal characteristics except 1 minute Apgar score (Supplement Table 2).

The incidences of RDS, hypotension within one week, PVL, moderate to severe BPD, and severe BPD were significantly higher in HS group when compared with IS and LS groups both before and after the propensity score matching (Supplement Table 3). Both univariate logistic regression analysis after the propensity score matching and multivariate logistic regression analysis with random intercepts adjusting for GA and the hospital groups according to the mean annual number of VLBW infants registered in the KNN after the propensity score matching showed an increased OR $(>1)$ for mortality, moderate to severe BPD and/or death, and PVL in HS group when compared with IS group and with LS group. Also, the OR of survival without major morbidities in the HS group was significantly decreased $(<1)$ in the HS group when compared with the IS and LS groups both before and after the propensity score matching (Supplement Table 4 ). 


\begin{tabular}{|c|c|c|c|c|c|c|}
\hline & \multicolumn{3}{|c|}{ Univariate logistic regression } & \multicolumn{3}{|c|}{$\begin{array}{l}\text { Multivariate logistic regression adjusted for } \\
\text { gestational age and groups according to the mean } \\
\text { annual number of very-low-birth-weight infants }\end{array}$} \\
\hline & $\begin{array}{l}\text { IS group versus } \\
\text { LS group }\end{array}$ & $\begin{array}{l}\text { HS group } \\
\text { versus IS group }\end{array}$ & $\begin{array}{l}\text { HS group versus } \\
\text { LS group }\end{array}$ & $\begin{array}{l}\text { IS group versus } \\
\text { LS group }\end{array}$ & \begin{tabular}{|l|} 
HS group \\
versus IS group
\end{tabular} & $\begin{array}{l}\text { HS group versus } \\
\text { LS group }\end{array}$ \\
\hline Death & $1.3(0.95-1.86)$ & $1.5(1.11-1.99)$ & $2.0(1.44-2.71)$ & $1.1(0.79-1.66)$ & $2.0(1.39-2.76)$ & $2.2(1.57-3.19)$ \\
\hline $\begin{array}{l}\text { Moderate to severe } \\
\text { BPD }\end{array}$ & $1.1(0.90-1.45)$ & $1.5(1.20-1.91)$ & $1.7(1.37-2.18)$ & $1.2(0.90-1.51)$ & $1.7(1.34-2.24)$ & $2.0(1.57-2.61)$ \\
\hline Severe BPD & $1.2(0.89-1.63)$ & $1.7(1.29-2.27)$ & $2.1(1.55-2.75)$ & $1.2(0.87-1.66)$ & $2.0(1.45-2.69)$ & $2.4(1.74-3.24)$ \\
\hline $\begin{array}{l}\text { Moderate to severe } \\
\text { BPD or death }\end{array}$ & $1.2(0.96-1.47)$ & $1.6(1.30-1.96)$ & $1.9(1.54-2.34)$ & $1.2(0.93-1.51)$ & $1.9(1.50-2.42)$ & $2.3(1.78-2.87)$ \\
\hline Severe BPD or death & $1.2(0.98-1.59)$ & $1.7(1.36-2.14)$ & $2.1(1.69-2.68)$ & $1.2(0.92-1.59)$ & $2.1(1.65-2.80)$ & $2.6(1.99-3.40)$ \\
\hline PVL & $1.2(0.84-1.86)$ & $1.6(1.07-2.27)$ & $1.9(1.34-2.82)$ & $1.3(0.85-1.89)$ & $1.5(1.06-2.26)$ & $2.0(1.34-2.86)$ \\
\hline $\begin{array}{l}\text { Survival without major } \\
\text { morbidities* }\end{array}$ & $1.1(0.89-1.34)$ & $0.7(0.54-0.83)$ & $0.7(0.59-0.91)$ & $1.1(0.90-1.38)$ & $0.7(0.53-0.83)$ & $0.7(0.59-0.92)$ \\
\hline
\end{tabular}

Table 5. Logistic regression analysis with random effect after propensity score matching. *Major morbidities include moderate to severe $\mathrm{BPD}, \mathrm{NEC} \geq$ stage $2, \mathrm{IVH} \geq$ grade $3, \mathrm{PVL}$, ROP requiring surgery or VEGF. HS; high sepsis, IS; intermediate sepsis, LS; low sepsis, BPD; bronchopulmonary dysplasia, PVL; periventricular leukomalacia.

\section{Discussion}

In this study using nationwide database, we demonstrated that the incidence of sepsis showed considerable center-to-center variability in Korea. This difference remained significant even after the propensity score matching for multiple antenatal and perinatal factors including GA and gender. In our study, the sepsis rate serially increased from the LS, IS to the HS group. The rate of LOS was also increased from the LS group to the HS group, and especially gram-positive sepsis was more frequent in the HS group (79\%) when compared with the LS group $(61 \%)$. The maternal demographics and neonatal general characteristics showed that the GA and birthweight were higher in the LS group when compared with the IS and HS groups; however, there was no significant difference in GA and birthweight between the IS group and the HS group. After the propensity score matching for such different general characteristics, the neonatal outcomes were worse in the HS group when compared with the LS and IS groups; however, there was no significant difference in neonatal outcomes between the LS and IS groups. When we performed the same analyses in infants without EOS, the results were also same.

A study by the National Institute of Child Health and Human Development Neonatal Research Network (NICHD) on 6,215 infants who survived beyond 3 days showed that the rate of LOS for at least one episode was $21 \%$, and the rate for the first episode of LOS was 3.1 per 1,000 patient days, which are similar to our results ${ }^{1}$. In the Canadian Neonatal Network, $15 \%$ of infants with less than 32 weeks of gestation suffered from LOS, and bacterial late-onset sepsis was associated with mortality and $\mathrm{BPD}^{3}$. They concluded that the risk factors for LOS were a lower gestation, higher Score for Neonatal Acute Physiology (version II scores), the presence of prolonged use of central catheters, parenteral nutrition, and nothing by mouth ${ }^{3}$. In our study, similar results were seen in that the GA in the LS group was significantly higher when compared to the IS or HS group. In the LS group, days to full feeding were shorter with 14 postnatal days when compared to the HS group with 19 postnatal days until full feeding.

In our study, a group of infants with a higher sepsis rate had poorer neonatal outcomes even when there were no significant differences in GA and birthweight between the IS and HS groups. Because we did not assess whether sepsis itself is an independent risk factor of mortality, BPD, and PVL in this study, we still cannot determine whether sepsis itself was the direct leading cause of the poorer neonatal outcomes or other factors that were associated with a higher sepsis rate led to such poorer neonatal outcomes. From many previous reports, numerous evidence has shown that sepsis itself is associated with increased mortality, BPD, and long-term neurodevelopmental outcomes in preterm infants ${ }^{1-5}$. Additionally, the many nationwide quality improvements by nationwide neonatal networks, such as Vermont-Oxford Network ${ }^{6}$ and Canadian Neonatal Network ${ }^{14}$, to reduce sepsis in units with a high sepsis rate, especially focusing on the LOS, were the most effective in improving neonatal outcomes ${ }^{6,14}$. Such a reduction in LOS also improved the survival of extremely preterm infants born at 23-26 weeks of gestation in a single tertiary hospital ${ }^{15}$. Moreover, quality improvement can have a spill-over effect from one outcome to another, and many common strategies are used to improve different outcomes. For example, the nosocomial infection rate was decreased not only in the evidence-based practice from improving quality methods (EPIQ) infection group but also in the EPIQ pulmonary group in the EPIQ trial by the Canadian Neonatal Network, which implies that decreasing the duration of invasive ventilator care is another important method to reduce the sepsis rate ${ }^{14}$. Nowadays, the Canadian Neonatal Network and Vermont-Oxford Network have adopted a multi-targeting quality improvement campaign simultaneously to improve the composite of morbidity and major neonatal outcomes, especially in extremely low GA infants ${ }^{16,17}$. That is why we think that nationwide quality improvement to control sepsis should be started first in Korea, considering that we cannot start multiple strategies for quality improvement at once.

In our study, in only the HS group, the mortality and BPD were increased. Actually, the gap in the incidence density of sepsis is larger between the HS and IS groups when compared with the gap between the IS and LS groups in our study population. Thus, decreasing the sepsis rate in the HS group will be very important and will be a main target of quality improvement in NICUs. Among the LOS infants, coagulase-negative staphylococcus 


\begin{tabular}{|c|c|c|c|c|c|c|c|c|}
\hline & \multicolumn{8}{|c|}{ Propensity score matching } \\
\hline & \multicolumn{4}{|c|}{ Unmatched dataset $(N=7,493)$} & \multicolumn{4}{|c|}{ Matched dataset $(\mathrm{N}=2,538)$} \\
\hline & $\begin{array}{l}\text { Low sepsis } \\
\text { group }\end{array}$ & $\begin{array}{l}\text { Intermediate } \\
\text { sepsis group }\end{array}$ & $\begin{array}{l}\text { High sepsis } \\
\text { group }\end{array}$ & P-value & $\begin{array}{l}\text { Low sepsis } \\
\text { group }\end{array}$ & $\begin{array}{l}\text { Intermediate } \\
\text { sepsis group }\end{array}$ & $\begin{array}{l}\text { High sepsis } \\
\text { group }\end{array}$ & P-value \\
\hline Gram positive organisms & $90(60.8 \%)$ & $535(68.9 \%)$ & $767(78.6 \%)$ & $<0.001^{* *, \dagger}$ & $42(56.8 \%)$ & $128(76.6 \%)$ & $328(79.6 \%)$ & $<0.001^{*, * * *}$ \\
\hline Staphylococcus coagulase negative & $35(23.6 \%)$ & $253(32.6 \%)$ & $428(43.9 \%)$ & & $17(23.0 \%)$ & $50(29.9 \%)$ & $174(42.2 \%)$ & \\
\hline $\begin{array}{l}\text { Staphylococcus aureus coagulase } \\
\text { positive }\end{array}$ & $18(12.2 \%)$ & $106(13.6 \%)$ & $104(10.7 \%)$ & & $6(7.6 \%)$ & $37(21.8 \%)$ & $53(12.6 \%)$ & \\
\hline Staphylococcus other & $17(11.5 \%)$ & $97(12.5 \%)$ & $117(12.0 \%)$ & & $7(9.5 \%)$ & $22(13.2 \%)$ & $61(14.8 \%)$ & \\
\hline Streptococcus other & $5(3.4 \%)$ & $17(2.2 \%)$ & $11(1.1 \%)$ & & $4(5.4 \%)$ & $4(2.4 \%)$ & $1(0.2 \%)$ & \\
\hline Streptococcus group B & $8(5.4 \%)$ & $12(1.5 \%)$ & $9(0.9 \%)$ & & $5(6.8 \%)$ & $3(1.8 \%)$ & $2(0.5 \%)$ & \\
\hline Enterococcus species & $7(4.7 \%)$ & $49(6.3 \%)$ & $98(10.0 \%)$ & & $3(4.1 \%)$ & $12(7.2 \%)$ & $38(9.2 \%)$ & \\
\hline Listeria species & $0(0.0 \%)$ & $1(0.1 \%)$ & $0(0.0 \%)$ & & $0(0.0 \%)$ & $0(0.0 \%)$ & $0(0.0 \%)$ & \\
\hline Gram negative organisms & $37(25.0 \%)$ & $163(21.0 \%)$ & $125(12.8 \%)$ & $<0.001^{* *, \dagger}$ & $22(29.7 \%)$ & $28(16.8 \%)$ & $57(13.8 \%)$ & $0.003^{* *}$ \\
\hline Escherichia coli & $13(8.8 \%)$ & $37(4.8 \%)$ & $21(2.2 \%)$ & & $6(8.1 \%)$ & $10(6.0 \%)$ & $12(2.9 \%)$ & \\
\hline Klebsiella species & $10(6.8 \%)$ & $34(4.4 \%)$ & $23(2.4 \%)$ & & $7(9.5 \%)$ & $4(2.4 \%)$ & $12(2.9 \%)$ & \\
\hline Pseudomonas species & $3(2.0 \%)$ & $8(1.0 \%)$ & $14(1.4 \%)$ & & $1(1.4 \%)$ & $2(1.2 \%)$ & $5(1.2 \%)$ & \\
\hline Acinetobacter species & $4(2.7 \%)$ & $20(2.6 \%)$ & $9(0.9 \%)$ & & $3(4.1 \%)$ & $3(1.8 \%)$ & $4(1.0 \%)$ & \\
\hline Enterobacter species & $4(2.7 \%)$ & $33(4.2 \%)$ & $28(2.9 \%)$ & & $3(4.1 \%)$ & $6(3.6 \%)$ & $13(3.2 \%)$ & \\
\hline Burkholderia species & $0(0.0 \%)$ & $16(2.1 \%)$ & $3(0.3 \%)$ & & $0(0.0 \%)$ & $2(1.2 \%)$ & $1(0.2 \%)$ & \\
\hline Clostridium species & $0(0.0 \%)$ & $1(0.1 \%)$ & $0(0.0 \%)$ & & $0(0.0 \%)$ & $0(0.0 \%)$ & $0(0.0 \%)$ & \\
\hline Stenotrophomonas maltophilia & $1(0.7 \%)$ & $3(0.4 \%)$ & $4(0.4 \%)$ & & $1(1.4 \%)$ & $0(0.0 \%)$ & $1(0.2 \%)$ & \\
\hline Achromobacter species & $1(0.7 \%)$ & $0(0.0 \%)$ & $0(0.0 \%)$ & & $1(1.4 \%)$ & $0(0.0 \%)$ & $0(0.0 \%)$ & \\
\hline Citrobacter species & $0(0.0 \%)$ & $1(0.1 \%)$ & $0(0.0 \%)$ & & $0(0.0 \%)$ & $0(0.0 \%)$ & $0(0.0 \%)$ & \\
\hline Hemophilus species & $0(0.0 \%)$ & $1(0.1 \%)$ & $1(0.1 \%)$ & & $0(0.0 \%)$ & $0(0.0 \%)$ & $0(0.0 \%)$ & \\
\hline Moraxella species & $0(0.0 \%)$ & $0(0.0 \%)$ & $1(0.1 \%)$ & & $0(0.0 \%)$ & $0(0.0 \%)$ & $0(0.0 \%)$ & \\
\hline Proteus species & $0(0.0 \%)$ & $1(0.1 \%)$ & $0(0.0 \%)$ & & $0(0.0 \%)$ & $0(0.0 \%)$ & $0(0.0 \%)$ & \\
\hline Serratia species & $1(0.7 \%)$ & $8(1.0 \%)$ & $16(1.6 \%)$ & & $0(0.0 \%)$ & $1(0.6 \%)$ & $6(1.5 \%)$ & \\
\hline Bacteroides species & $0(0.0 \%)$ & $0(0.0 \%)$ & $5(0.5 \%)$ & & $0(0.0 \%)$ & $0(0.0 \%)$ & $3(0.7 \%)$ & \\
\hline Fungus & $12(8.1 \%)$ & $65(8.4 \%)$ & $71(7.3 \%)$ & 0.691 & $5(6.8 \%)$ & $8(4.8 \%)$ & $23(5.6 \%)$ & 0.788 \\
\hline Candida & $10(6.8 \%)$ & $63(8.1 \%)$ & $65(6.7 \%)$ & & $5(6.8 \%)$ & $8(4.8 \%)$ & $21(5.1 \%)$ & \\
\hline Yeast, others & $2(1.4 \%)$ & $2(0.3 \%)$ & $6(0.6 \%)$ & & $0(0.0 \%)$ & $0(0.0 \%)$ & $2(0.5 \%)$ & \\
\hline Others & $9(6.1 \%)$ & $14(1.8 \%)$ & $13(1.3 \%)$ & $0.002^{*, * *}$ & $5(6.8 \%)$ & $3(1.8 \%)$ & $4(1.0 \%)$ & $0.007^{* *}$ \\
\hline Total & $148(100.0 \%)$ & 777 (100.0\%) & $976(100.0 \%)$ & & $74(100.0 \%)$ & $167(100.0 \%)$ & $412(100.0 \%)$ & \\
\hline
\end{tabular}

Table 6. Distribution of Pathogens among three groups both in unmatched and matched dataset. Organisms counts differ from the infants with sepsis due to the multiple episode of sepsis. $* \mathrm{P}<0.05$ between low sepsis group and intermediate sepsis group. ${ }^{* *} \mathrm{P}<0.05$ between low sepsis group and high sepsis group. ${ }^{\dagger} \mathrm{P}<0.05$ between intermediate sepsis group and high sepsis group.

(CONS) is known to be the most prevalent cause of sepsis ${ }^{12}$; however, gram-negative or fungal sepsis is known to be associated with the highest risk of mortality or adverse outcomes in preterm infants ${ }^{3,18}$. CONS is also a well-known bacteria associated with an increased risk of $\mathrm{BPD}^{19,20}$. Gram-positive organisms are usually associated with catheter-related bloodstream infection, and gram-negative organisms are more commonly seen in NEC patients ${ }^{18}$. In our cohort, CONS was the most prevalent causal organisms of sepsis, especially in the HS group, and there was no significant difference in the prevalence of fungal sepsis between the three groups. A quality improvement program with strategies to reduce CONS sepsis such as a central catheter bundle, reducing the duration of central catheter insertion, and hand washing will be important in improving neonatal outcomes in the NICUs of South Korea. Because the duration of invasive ventilator care and the days to full feeding were longer in the HS group, reducing invasive ventilation, prompt extubation as soon as possible, and an earlier start of enteral feeding will be also helpful to reduce the sepsis rate and to improve neonatal outcomes.

Many previous reports showed that there are variations in practice and in neonatal outcomes between NICUs ${ }^{8}$. Moreover, there was a significant disparity in the sepsis incidence between units, which is common in other countries $^{9-11}$. In the NICHD cohort, there was center-to-center variability in the incidence of LOS ranging from $10.6 \%$ to $31.7 \%^{1}$. In our study population, the median sepsis rate was $6.7 \%$ in the LS group; however, it approached $36.2 \%$ in the HS group. Actually, there was no significant difference in the maternal demographics and neonatal baseline characteristics between the IS and HS groups in our study. However, the neonatal outcome was worse in the HS group when compared with the IS group, which implies that other factors besides GA and birth weight might influence the neonatal outcomes in each NICU. The Canadian Neonatal Network searched for the risk factors for the variations in the rates of nosocomial infections among each unit, and after adjusting for risk factors associated with nosocomial infections such as GA, birth weight, and disease severity, there was still a difference in the rate of nosocomial infections between units ${ }^{11}$. However, there was little doubt that the nosocomial infections 
were associated with significant in-hospital morbidities in that study ${ }^{11}$. In our study, only in the HS group, adverse neonatal morbidities were more frequent.

To reduce the gap in the sepsis incidence rate between units, assessing which factors were different in relation to the occurrence of sepsis and searching for the factors associated with sepsis in the units with the lowest and highest infection rates would be helpful to identify the medical or nursing care practices influencing the sepsis rate. According to previous reports, number of days of central catheter insertion and total parenteral nutrition, resuscitation at birth, status of infants on admission, patient load or nurse to patient ratio were very important risk factors of sepsis ${ }^{3,9,10}$. Besides well-known risk factors of sepsis such as GA and patient status at admission, the differences in daily clinical practices caused the center-to-center variation of the sepsis rate ${ }^{11}$. Unfortunately, in this study, we could not get such information from the KNN database; we could only get the information about the group of mean annual number of VLBW infants registered in KNN, which showed no significant difference between three groups. When we performed the multivariate logistic regression analysis with random intercepts adjusting for GA and the hospital groups after the propensity score matching, the results were not much changed from those of the analysis with multivariate logistic regression only adjusting for GA after propensity score matching. Those groups can represent some portion or quality of the NICU size; however, more information about the NICU levels, i,e, secondary, tertiary, or quarternary units, the presence of other supporting parts such as neonatal surgery, and the presence of a perinatal center or regional NICU center are needed to be judged first whether the hospital level influences the sepsis rate. Thus, a further prospective large cohort study is needed to find such risk factors.

In contrast to other reports ${ }^{21}$, the length of stay in hospital was not different between the three groups after the propensity score matching in the survivors of our cohort. However, the duration of invasive ventilator care or respiratory support and days to full feeding were longer in the HS group, which were similar to the results in other reports ${ }^{1}$. It means that the disease severity of the infants in the HS group was higher than that in the LS and IS groups. Especially, between the IS and HS groups, there was no difference in the GA and birth weight; however, morbidities, duration of invasive ventilator care, and the duration of hospitalization were longer in the HS group. Additionally, a longer duration of ventilator care and longer days to full feeding, which could suggest a longer duration of central catheter insertion, are well-known risk factors of sepsis.

The limitations of our study were as follows; first, we could not perform a cluster analysis at the individual hospital level at which the individual infant was admitted because it was a policy that the KNN did not provide any data about the individual hospital at which any infant was admitted. We tried to compensate for those problems by performing the multivariate logistic regression analysis with random intercepts adjusting for the hospital groups divided according to the number of registered VLBWs in the KNN. Second, we still could not clearly determine whether sepsis itself or other factors associated with a higher sepsis rate led to such poorer neonatal outcomes. Further studies should be done focusing on this problem. Third, we could not collect information about the duration of central catheter use although days to full feeding can be an indicator suggesting the duration of central catheter use. We also could not get information on staff such as the nurse to patient ratio and the unit size such as tertiary or secondary hospital. Further studies will be needed to determine the risk factors that lead to the difference in the incidence of sepsis between the three groups including the staff and facilities of the NICUs. Fourth, we could not determine the order of the outcomes, so we could not determine the cause and result relationships between sepsis and other outcomes except for BPD or ROP. That' is why we performed logistic regression analysis for only death, BPD, PVL, and survival without major morbidities. Fifth, we could not get information on the duration of antibiotic use and the antibiotic resistances of each organism from our KNN database. Considering that antibiotic resistance can also be a risk factor for a longer duration of antibiotic use and disease severity, a more sophisticated design for a prospective study including such information should be done later.

However, the strength of our study is that we used a nationwide cohort with a large sample size including almost all the neonates born from NICUs in South Korea. Our study cohort was also achieved by standardized data collection, which improved the accuracy of the data analysis. Moreover, this study is the first report to demonstrate the differences in neonatal outcomes according to the different units with variable sepsis rates in South Korea.

\section{Conclusion}

The sepsis rate was markedly different from the LS group to the HS group ranging from $6.7 \%$ to $36.2 \%$. The gap in the incidence of sepsis between the IS and HS groups was higher than the gap between the LS and IS groups. The GA and birthweight were more mature and heavier in the LS group when compared with the IS or HS group; however, there was no difference in the GA and birthweight between the IS and HS groups. Adverse neonatal outcomes including mortality, BPD, and PVL were higher in the HS group when compared with the LS and IS groups; however, there were no significant differences between the LS and IS groups, even after the propensity score matching. Other factors besides GA and birthweight in the HS group might be associated with worse neonatal outcomes. A future prospective cohort study that includes antibiotic use, patient care techniques, hand washing rate, and catheter insertion duration to assess the risk factors associated with center to center variability will be helpful to perform further nationwide interventions for quality improvement in infection control at NICUs.

\section{Methods}

Ethics statement. The KNN registry was approved by the institutional review board of each participating hospital including the Seoul Metropolitan Government Seoul National University (SMG-SNU) Boramae Medical Center (IRB number 26-2014-12). The names of all the participating hospitals were listed in the acknowledgement section. Informed consent was obtained from the parents and/or legal guardians of all the study participants at enrollment. All data collection was performed prospectively according to the guidelines and regulations of 
the KNN. All the researchers in each hospital put their data on digitally recording online case record forms, and such data are monitored regularly by KNN data management committee. The screening failure rate of KNN registry was $3.7 \%$ in 2016 . The present study was approved by the KNN data management committee, and the IRB approval was exempted by the SMG-SNU Boramae Medical Center (IRB number 07-2018-4).

Study population. This was a population-based observational study of VLBW infants born between 2013 and 2016, registered in the KNN database. The exclusion criteria were infants transferred to a ward, pediatric intensive care unit or other hospital, infants with major congenital anomalies, infants with no data about sepsis, and infants admitted for more than one year. Then, infants were classified into the LS, IS, or HS group according to the sepsis rate at each hospital. Propensity score matching was done to compensate for the differences in the maternal and neonatal demographic characteristics.

Data collection and analysis. The data for the infants were generated and analyzed from the KNN database. Mother-related variables were compared such as maternal age, multiple pregnancies, in vitro fertilization, delivery mode, gestational diabetes, hypertensive disorders of pregnancy, HCA, and oligohydramnios. Neonate-related variables were also compared including GA, birthweight, gender, SGA, complete course of ACS use, delivery room resuscitation, and 1- and 5-minute Apgar scores. We also compared the distribution of groups according to the mean annual number of VLBW infants registered in KNN database. The following outcomes were collected for the analysis: mortality, RDS, PDA with treatment, BPD, IVH $\geq$ grade 3 for the Papile classification $^{22}, \mathrm{NEC} \geq$ stage 2 for the modified Bell's criteria ${ }^{23}$, retinopathy of prematurity (ROP) requiring surgery or vascular endothelial growth factor (VEGF) treatment, discharge with respiratory support, the duration of hospitalization, and the duration of ventilator care and total respiratory support, and days to full feeding. And we compared the distribution of pathogens among LS, IS, and HS groups.

Definitions. Sepsis was defined as the presence of clinical symptoms and signs with proven causative organisms documented from blood cultures, and the patients should receive at least five days of antibiotics as a sepsis treatment. If more than one organism was grown in the blood culture simultaneously, the decision about the causal organism is dependent on the opinion of the physician. If the organisms were identified from a specimen obtained within 3 postnatal days, it was defined as EOS. If the organisms were identified from a specimen obtained after 3 or more postnatal days, it was defined as LOS.

Infants were classified into the LS, IS, and HS group according to the percentile of sepsis incidence in each hospital. The LS, IS, and HS groups were defined as follows: when the sepsis incidence was less than 25 percentile, 25-74 percentile, and more than 75 percentile in the whole KNN registered hospital.

The sepsis (incidence) rate was calculated as the number of neonates who suffered from sepsis at least one time during hospitalization divided by the total number of neonates in each group. The incidence density of sepsis was calculated as the number of episodes of sepsis divided by the number of patient-days at risk.

We categorized our participating hospitals according to the mean annual number of VLBW infants registered in the KNN. The criteria were as following; group $1<10$ (patients per year), $10 \leq$ group $2<20,20 \leq$ group $3<30,30 \leq$ group $4<40,40 \leq$ group $5<50,50 \leq$ group $6<100$, and group $7 \geq 100$.

SGA was defined as a birthweight less than the $10^{\text {th }}$ percentile based on the growth curve of Olsen et al. ${ }^{24}$ Hypertensive disorders of pregnancy were defined as any maternal diagnoses of chronic hypertension or pregnancy induced hypertension including preeclampsia, eclampsia, or hemolysis, elevated liver enzymes, and low platelet count syndrome. HCA was defined and classified using the grading by Salafia et al. ${ }^{25}$ Oligohydramnios was defined as amniotic fluid index $<5$. Delivery room resuscitation was defined as any cardiac compression or administration of medication in the delivery room. Complete course of ACS use was defined as the administration of 4 doses of dexamethasone or 2 doses of betamethasone, and the initial dose was given more than 24 hours and less than 7 days before birth. RDS was defined as chest radiographic findings consistent with RDS such as a diffuse ground glass appearance together with an oxygen requirement of more than 0.4 fractions of inspired oxygen $^{26}$. Surfactant use was defined as the administration of any surfactant use regardless of purpose. PDA with treatment was defined as any pharmacologic or surgical treatment about preterm PDA. BPD was defined and classified according to the definition by Jobe $\mathrm{AH}$ et al. ${ }^{27}$. Pulmonary hypertension requiring treatment was defined as any inhaled nitric oxide, sildenafil, iloprost, bosentan, milrinone treatment for pulmonary hypertension. We defined the duration of invasive ventilator care as the duration of ventilator support by endotracheal tube. We also defined the duration of respiratory support as the whole duration of any invasive/non-invasive ventilator care or oxygen support during hospitalization.

Statistical analysis. All the continuous variables were expressed as the median and interquartile range (IQR), and the categorical variables were expressed as the numbers and proportions. Comparisons of the maternal demographics and neonatal characteristics among the LS, IS, and HS groups were performed using one-way analysis of variance (ANOVA) test for continuous variables and chi-square test for categorical variables. Comparison of the groups according to the mean annual number of VLBW infants registered in KNN was performed using Kruskal-Wallis test. For multiple comparisons, Bonferroni correction was applied. Because the GA and birthweight were significantly higher in the LS group when compared with the IS or HS group and there were significant differences in the many maternal and neonatal demographics among the three groups, propensity score matching was considered to minimize the selection bias. To derive the propensity scores, multivariate logistic regression for the pairwise groups was conducted with GA, gender, SGA, multiple pregnancies, cesarean section, hypertensive disorders of pregnancy, HCA, oligohydramnios, complete course of steroid use, delivery room resuscitation, and 5-minute Apgar score. Since the correlation between GA and birthweight was highly positive, only GA was included as an adjusting factor in the propensity score matching. By first matching the LS to IS, 
LS to HS, and the IS and HS groups based on their propensity scores using the nearest neighbor matching algorithm, three-group propensity score matched dataset was generated. Univariate and multivariate logistic regression analyses with random intercepts were performed to account for hospital group effects according to the mean annual number of VLBWs registered in $\mathrm{KNN}$, with adjustment for GA on mortality, moderate to severe BPD, severe BPD, PVL, and survival without major morbidities (moderate to severe BPD, NEC $\geq$ stage 2 , IVH $\geq$ grade 3 , PVL, ROP requiring surgery or VEGF treatment) in matched sets. Comparison of the distribution of pathogens between three groups were performed by chi-square test. All analyses were performed with $\mathrm{R}$ version 3.5.0 (http://www.r-project.org) with the statistical significance set at a $P$-value $<0.05$.

\section{Data availability}

The dataset analyzed in this study are not publicly available due to the policy of Research of Korea Centers for Disease Control and Prevention. However, dataset are available from the corresponding author on reasonable request.

Received: 23 April 2019; Accepted: 6 April 2020;

Published online: 21 April 2020

\section{References}

1. Stoll, B. J. et al. Late-onset sepsis in very low birth weight neonates: the experience of the NICHD Neonatal Research Network. Pediatrics 110, 285-291 (2002).

2. Mitha, A. et al. Neonatal infection and 5-year neurodevelopmental outcome of very preterm infants. Pediatrics 132, e372-380, https://doi.org/10.1542/peds.2012-3979 (2013).

3. Shah, J., Jefferies, A. L., Yoon, E. W., Lee, S. K. \& Shah, P. S. Risk Factors and Outcomes of Late-Onset Bacterial Sepsis in Preterm Neonates Born at $<32$ Weeks' Gestation. American journal of perinatology 32, 675-682, https://doi.org/10.1055/s-0034-1393936 (2015).

4. Schlapbach, L. J. et al. Impact of sepsis on neurodevelopmental outcome in a Swiss National Cohort of extremely premature infants. Pediatrics 128, e348-357, https://doi.org/10.1542/peds.2010-3338 (2011).

5. Ohlin, A., Bjorkman, L., Serenius, F., Schollin, J. \& Kallen, K. Sepsis as a risk factor for neonatal morbidity in extremely preterm infants. Acta paediatrica (Oslo, Norway: 1992) 104, 1070-1076, https://doi.org/10.1111/apa.13104 (2015).

6. Kilbride, H. W., Wirtschafter, D. D., Powers, R. J. \& Sheehan, M. B. Implementation of evidence-based potentially better practices to decrease nosocomial infections. Pediatrics 111, e519-533 (2003).

7. Kusuda, S. et al. Morbidity and mortality of infants with very low birth weight in Japan: center variation. Pediatrics 118, e1130-1138, https://doi.org/10.1542/peds.2005-2724 (2006).

8. Lee, S. K. et al. Variations in practice and outcomes in the Canadian NICU network: 1996-1997. Pediatrics 106, 1070-1079 (2000).

9. Boo, N. Y. \& Cheah, I. G. Factors associated with inter-institutional variations in sepsis rates of very-low-birth-weight infants in 34 Malaysian neonatal intensive care units. Singapore medical journal 57, 144-152, https://doi.org/10.11622/smedj.2016056 (2016).

10. Chien, L. Y. et al. Variations in central venous catheter-related infection risks among Canadian neonatal intensive care units. The Pediatric infectious disease journal 21, 505-511 (2002).

11. Aziz, K. et al. Variations in rates of nosocomial infection among Canadian neonatal intensive care units may be practice-related. BMC pediatrics 5, 22, https://doi.org/10.1186/1471-2431-5-22 (2005).

12. Lee, S. M., Chang, M. \& Kim, K. S. Blood Culture Proven Early Onset Sepsis and Late Onset Sepsis in Very-Low-Birth-Weight Infants in Korea. Journal of Korean medical science 30(Suppl 1), S67-74, https://doi.org/10.3346/jkms.2015.30.S1.S67 (2015).

13. Lee, J. H., Noh, O. K. \& Chang, Y. S. Neonatal Outcomes of Very Low Birth Weight Infants in Korean Neonatal Network from 2013 to 2016. Journal of Korean medical science 34, e40, https://doi.org/10.3346/jkms.2019.34.e40 (2019).

14. Lee, S. K., Aziz, K., Singhal, N. \& Cronin, C. M. The Evidence-based Practice for Improving Quality method has greater impact on improvement of outcomes than dissemination of practice change guidelines and quality improvement training in neonatal intensive care units. Paediatrics \& child health 20, e1-9 (2015).

15. Kim, J. K., Chang, Y. S., Sung, S., Ahn, S. Y. \& Park, W. S. Trends in the incidence and associated factors of late-onset sepsis associated with improved survival in extremely preterm infants born at 23-26 weeks' gestation: a retrospective study. BMC pediatrics 18, 172, https://doi.org/10.1186/s12887-018-1130-y (2018).

16. Lee, S. K. et al. Outcomes and care practices for preterm infants born at less than 33 weeks' gestation: a quality-improvement study. CMAJ: Canadian Medical Association journal = journal de l'Association medicale canadienne 192, E81-e91, https://doi.org/10.1503/ cmaj.190940 (2020).

17. Kaempf, J. W. et al. Sustained quality improvement collaboration and composite morbidity reduction in extremely low gestational age newborns. Acta paediatrica (Oslo, Norway: 1992) 108, 2199-2207, https://doi.org/10.1111/apa.14895 (2019).

18. Tsai, M. H. et al. Incidence, clinical characteristics and risk factors for adverse outcome in neonates with late-onset sepsis. The Pediatric infectious disease journal 33, e7-e13, https://doi.org/10.1097/INF.0b013e3182a72ee0 (2014).

19. Anderson-Berry, A., Brinton, B., Lyden, E. \& Faix, R. G. Risk factors associated with development of persistent coagulase-negative staphylococci bacteremia in the neonate and associated short-term and discharge morbidities. Neonatology 99, 23-31, https://doi. org/10.1159/000292567 (2011).

20. Liljedahl, M., Bodin, L. \& Schollin, J. Coagulase-negative staphylococcal sepsis as a predictor of bronchopulmonary dysplasia. Acta paediatrica (Oslo, Norway: 1992) 93, 211-215 (2004).

21. Pessoa-Silva, C. L. et al. Neonatal late-onset bloodstream infection: attributable mortality, excess of length of stay and risk factors. European journal of epidemiology 17, 715-720 (2001).

22. Papile, L. A., Burstein, J., Burstein, R. \& Koffler, H. Incidence and evolution of subependymal and intraventricular hemorrhage: a

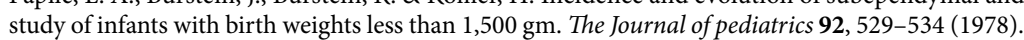

23. Bell, M. J. et al. Neonatal necrotizing enterocolitis. Therapeutic decisions based upon clinical staging. Annals of surgery 187, 1-7 (1978).

24. Olsen, I. E., Groveman, S. A., Lawson, M. L., Clark, R. H. \& Zemel, B. S. New intrauterine growth curves based on United States data. Pediatrics 125, e214-224, https://doi.org/10.1542/peds.2009-0913 (2010).

25. Salafia, C. M., Weigl, C. \& Silberman, L. The prevalence and distribution of acute placental inflammation in uncomplicated term pregnancies. Obstetrics and gynecology 73, 383-389 (1989).

26. Sweet, D. G. et al. European Consensus Guidelines on the Management of Respiratory Distress Syndrome - 2016 Update. Neonatology 111, 107-125, https://doi.org/10.1159/000448985 (2017).

27. Jobe, A. H. \& Bancalari, E. Bronchopulmonary dysplasia. American journal of respiratory and critical care medicine 163, 1723-1729, https://doi.org/10.1164/ajrccm.163.7.2011060 (2001). 


\section{Acknowledgements}

This research was supported by a fund (code-2016-ER6307-00) by Research of Korea Centers for Disease Control and Prevention. We thank the members of the Korean Neonatal Network for contribution. The names of the Korean Neonatal Network participating hospitals and corresponding principal investigators were as follows; Ajou University Hospital (Dr. Jang Hoon Lee), Asan Medical Center (Dr. Byong Sop Lee), Busan ST Mary's Hospital (Dr. Sung Mi Kim), CHA Bundang Medical Center, CHA University (Dr. Heui Seung Jo), CHA Gangnam Medical Center, CHA University(Dr. Ji Hyun Jeon), Cheil General Hospital \& Women's Healthcare Center (Dr. Sun Young Ko), Chonbuk National University Hospital (Dr. Jin Kyu Kim), Chonnam National University Hospital (Dr. Eun Song Song), Chosun University Hospital (Dr. Sang Kee Park), Chung-Ang University Hospital (Dr. Na Mi Lee), Chungbuk National University (Dr. Shin Ae Yoon), Chungnam National University Hospital (Dr. Mea Young Chang), Daegu Catholic University Medical Center (Dr. Woo Taek Kim), Dong-A University Hospital (Dr. Myo Jing Kim), Dongguk University Ilsan Hospital (Dr. Do Hyun Kim), Eulji General Hospital (Dr. Hye Sun Yoon), Eulji University Hospital (Dr. Seung Yeon Kim), Ewha Womans University Medical Center (Dr. Eun Ae Park), Gachon University Gil Medical Center (Dr. Dong Woo Son), Gangnam Severance Hospital (Dr. Soon Min Lee), GangNeung Asan Hospital (Dr. Hyun Seung Jin), Kangwon National University Hospital (Dr. Se Yeon Kim), Gyeongsang National University Hospital (Dr. Chan Hoo Park), Hallym University Medical Center kangnam Sacred Heart Hospital (Dr. Tae-Jung Sung), Hallym University Medical Center kangdong Sacred Heart Hospital (Dr. Su Yeong Kim), Hanyang University Medical Center (Dr. Hyun Kyung Park), Hanyang University Guri Hospital (Dr. Chang-Ryul Kim), Inha University Hospital (Dr. Joo Young Lee), Inje University Busan Paik Hospital (Dr. Ga-Won Jeon), Inje University Haeundae Paik Hospital (Dr. Mi Lim Chung), Inje University Ilsan Paik Hospital (Dr. Jong Hee Hwang), Inje University Sanggye Paik Hospital (Dr. Gyu Hong Shim), Jeju National University Hospital (Dr. Yun Ju Kim), Kangbuk Samsung Hospital (Dr. Jae Won Shim), Keimyung University Dongsan Medical Center (Dr. Chun Soo Kim), Konkuk University Medical Center (Dr. Hye-won Park), Konyang University Hospital (Dr. Jae Woo Kim), Korea University Anam Hospital (Dr. Eun Hee Lee), Korea University Ansan Hospital (Dr. Byung Min Choi), Korea University Guro Hospital (Dr. Young Sook Hong), Kosin University Gospel Hospital (Dr. Eugine Jeong), Kyung Hee University Hospital at Gangdong (Dr. Chong Woo Bae), Kyung Hee University Medical Center (Dr. Yong Sung Choi), Kyungpook National University Chilgok Hospital (Dr. Heng Mi Kim), Kyungpook National University Hospital (Dr. Heng Mi Kim), National Health Insurance Service Ilsan Hospital (Dr. Shin Won Yoon), Pusan National University Children's Hospital (Dr. Shin Yun Byun), Pusan National University Hospital (Dr. Kyung Hee Park), Samsung Changwon Medical Center (Dr. Young Don Kim), Samsung Medical Center (Dr. Won Soon Park), Seoul National University Bundang Hospital (Dr. Chang Won Choi), Seoul National University Hospital (Dr. Ee Kyung Kim), Severance Hospital (Dr. Ran Namgung), SMGSNU Boramae Medical Center (Dr. Jin A Lee), Soonchunhyang University Hospital Bucheon (Dr. Sung Shin Kim), Soonchunhyang University Hospital Cheonan (Dr. Jun Hwan Sing), Soonchunhyang University Hospital Seoul (Dr. Woo Ryoung Lee), Sungae Hospital (Dr. Eun Ryung Kim), The Catholic University of Korea Bucheon ST. Mary's Hospital (Dr. Ju Young Lee), The Catholic University of Korea Seoul ST. Mary's Hospital (Dr. In Kyung Sung), The Catholic University of Korea ST. Vincent's Hospital (Dr. Jung Hyun Lee), The Catholic University of Korea Uijeongbu ST. Mary's Hospital (Dr. Hyun Seung Lee), The Catholic University of Korea Yeouido ST. Mary's Hospital (Dr. So Young Kim), Ulsan University Hospital (Dr. ki Won Oh), Wonju Severance Christian Hospital (Dr. Byung Kook Lee), Wonkwang University School of Medicine \& Hospital (Dr. Seung Hyun Lee), Yeungnam University Hospital (Dr. Eun Sil Lee).

\section{Author contributions}

Sung T.J. and Lee J.A. designed research. Oh S. analyzed data. Sung T.J. and Lee J.A. wrote the manuscript. Sohn J.A. performed research and critically reviewed manuscript. All authors approved the final version of the manuscript.

\section{Competing interests}

The authors declare no competing interests.

\section{Additional information}

Supplementary information is available for this paper at https://doi.org/10.1038/s41598-020-63762-6.

Correspondence and requests for materials should be addressed to J.A.L.

Reprints and permissions information is available at www.nature.com/reprints.

Publisher's note Springer Nature remains neutral with regard to jurisdictional claims in published maps and institutional affiliations.

Open Access This article is licensed under a Creative Commons Attribution 4.0 International License, which permits use, sharing, adaptation, distribution and reproduction in any medium or format, as long as you give appropriate credit to the original author(s) and the source, provide a link to the Creative Commons license, and indicate if changes were made. The images or other third party material in this article are included in the article's Creative Commons license, unless indicated otherwise in a credit line to the material. If material is not included in the article's Creative Commons license and your intended use is not permitted by statutory regulation or exceeds the permitted use, you will need to obtain permission directly from the copyright holder. To view a copy of this license, visit http://creativecommons.org/licenses/by/4.0/.

(c) The Author(s) 2020 